\title{
Digital Pygmalion: The Symbolic and VISUAL CONSTRUCTION OF THE FEMININE IN COVERDOLL ONLINE MAGAZINE
}

\author{
Maria João Faustino
}

\begin{abstract}
This study aims to question and problematize the construction of gendered meanings and visual codes in the digital context. Rooted in the theoretical framework of cyberfemism, it analyzes the visual and linguistic content of CoverDoll, a monthly e-zine thematically devoted to sex dolls. The Pygmalion myth is proposed as the symbolic framework of CoverDoll, since the linguistic and pictorial devices that support a simulated subjectivity seem to reproduce its main backdrop: the feminine is constructed as alterity and a product of male desire. The analysis of CoverDoll's portfolio and fictional discourses suggests the persistence of symbolic and aesthetical conventions despite technological ruptures. The operating mechanisms in the tradition of painting described by John Berger seem resiliently translated into the visual construction of the feminine in CoverDoll: the portrayed feminine figure addresses a masculine voyeur which is absent from the picture. The camera replaces the mirror as a symbolic device of the projected female's narcissism, as the multiple references to the camera in the fictional discourses forge the idea of female vanity. The images displayed overall eroticize and objectify the artificial female bodies. The fictional narratives mobilize and intertwine a set of stereotypes that associate femininity with futility, seduction and caring.
\end{abstract}

KEYWORDS

CoverDoll; cyberfeminism; sex dolls; Pygmalion; Galatea

\begin{abstract}
ReSUMo
Partindo da moldura teórica do ciberfeminismo, e questionando a construção da visualidade no contexto digital e a dimensão de género que a baliza, o presente estudo centra-se na análise dos conteúdos imagéticos e linguísticos publicados na CoverDoll, revista online dedicada às sex dolls. O mito de Pigmalião é proposto como dispositivo hermenêutico na análise da CoverDoll, já que os mecanismos de simulação de uma subjetividade parecem reproduzir o mesmo fundo simbólico: o feminino ficcionado surge numa condição de alteridade, como produto do masculino criador. A nossa análise aponta para continuidades simbólicas e convenções estéticas que permanecem apesar das disrupções técnicas. A construção visual do feminino nas produções fotográficas da revista prolonga mecanismos operantes na tradição da pintura descritos por John Berger: o feminino retratado dirige-se a um voyeur masculino, ausente da imagem. A câmara é na CoverDoll sucedânea do espelho enquanto dispositivo de construção do feminino narcísico: pelas múltiplas referências à camara, a pretensa vaidade feminina surge como artifício de ocultação do voyeur masculino. Os conteúdos imagéticos convergem para a erotização e espectacularização do corpo feminino, tratando-o como objeto visual e traduzindo uma visão padronizada de beleza. As narrativas ficcionais articulam estereotipias do feminino: frivolidade, sedução e cuidado.
\end{abstract}

Palavras-Chave

CoverDoll; ciberfeminismo; sex dolls; Pigmalião; Galateia 
INTRODUCTION. RETHINKING THE GENDERED BODY FROM CYBERFEMINISM TO SEX DOLLS. Revisiting Pygmalion: Desire ANd ARTIFICE In TeChNological SOCIETY

The tradition of western thought - despite its several authorial, epochal and cultural nuances and differences - has mainly associated the body to illusion and error and symbolized it as a last remaining sight of animal condition, the source of minor desires that would require discipline through an ethical and epistemological commitment (Bordo, 1993, p. 3). Bordo refers to the Platonic representation of the corporeal prison, expressed in Fedon, as encapsulating the fundamental dualism between body and mind, spirit and freedom: a dualism that persisted through the Christian worldview and belief in a transcendent self, and that was also detectable across the multiple efforts to suppress the body in the pursuit of knowledge (Bordo, 1993, p. 3). This basic dualism is not neutral; on the contrary, it is structurally gendered, and the superiority of what is considered to transcend the body is classically associated with masculinity, rationality and intellectuality. Opposed to the intellectual order, the carnal dimension is classically connoted with femininity, an association rooted in Aristotelian philosophy (Price \& Shildrick, 1999, p. 17).

It was the same tradition of thought that Donna Haraway, in her influential A Manifesto for Cyborgs: Science, Technology, and Socialist Feminism in the 1980s (1985), diagnosed as structurally anchored in dualisms, basic antinomies that oppose nature and culture, body and mind, feminine and masculine. These forged antinomies did not presupposed an ontological or axiological symmetry; on the contrary, the imperium of the masculine self which epitomized western's rationality has imposed its path and power through domination over all difference and constituted alterity (1985). Haraway argues, though, that the emergence of a new ontology that fuses body and artifact, biology and technology, can lead to the erosion of such binaries and fixed identities. The concepts of human and animal, biological and mechanic, lose its stable and identifiable frontiers in the contemporary technological society: "we are all cyborgs", writes Haraway (1985). The caducity of classic ontological categories also means the caducity of fixed gender categories: the cyborg is a creature of a post-gender world, able to overcome the condition of alterity long attributed to women (1985).

Haraway's cyborg metaphor is part of a broader theoretical movement that embraced technological change and perceiving it as potentially reorganizing and restructuring conventional identities and gender hierarchies. Cyberfeminism - or cyberfeminisms, more accurately, since the concept covers different authorial perspectives (Daniels, 2013, p. 102) - problematizes the relations between gender, feminist practices and digital technologies (Daniels, 2013, p. 103). Theoretical positions that, in the matrix of Sadie Plant (1997), conceived cyberspace as promoting the suspension of body-based identities and saw it as potentiating a gender fluid interaction seem growingly supplanted by more nuanced visions and theoretical approaches, supported by empirical research concerning the uses and practices of digital technologies (Daniels, 2013).

On one hand, some theoretical positions underline the subversive potential of internet (Daniels, 2013, p. 109): Lisa Nakamura coined the concept of "identity tourism" 
to address the possibility of a self-camouflage, where a suppression of the body as the immediate social marker would allow a broader experience of one's identity $(2002$, p. 8); Sherry Turkle (1995) has early addressed virtual communities as potential laboratories of social experimentalism, that would enable a certain chameleonic virtual identity and social role recreation. Further on, problematizing the relations between internet and ethnic differentiation, Mark Hansen has talked about cyberspace as potentially neutralizing social markers, therefore opening more equitable interactional processes (2006, p. 141).

On the other hand, there are dissonant responses to this line of thought that question the linear emancipatory potential of the digital: Jessie Daniels has pointed out how specific ways of internet use by women and girls can both contest and reinforce gender and race hierarchies $(2013$, p. 101). This ambivalence is supported by the virtual ethnography of virtual communities anchored in traditional visions of body and gender, such as sites promoting anorexia as an aesthetical idea among adolescents (2013, pp. 112-115). Besides, the author contextualizes the techno euphoria of the first theoretical frameworks of cyberfeminism as contingent to an embryonic stage of internet characterized by textual communication - a referential challenged by subsequent networks and the plethora of online images, sounds and videos that enhanced graphic representations of the body.

Technological devices, methods and software that allow sophisticated image manipulation have already been problematized as tools used in the pursuit of a beauty ideal that suppresses actual bodily, aesthetic, ethnic and age diversity, contributing to the idealized aesthetics of femininity that constrains it to slimness and youth beauty standards (Wolf, 1991; Gill, 2007; Mota-Ribeiro, 2005). Contemporary photographic productions add a new scale to this process by virtually subtracting female idealized beauty to the ageing process, weight fluctuations, unwanted hair and skin alleged imperfections. Virtual mannequins ultimately overcome all these inevitable features and processes, unescapable to real embodied women: they never age, are presented as physical flawless and make absolutely no demands (Gills, 2007).

Sex dolls, the inspirational theme and background of CoverDoll, can also be approached within the same paradigm of artificial female beauty standards and production. The Pygmalion myth has been proposed as a hermeneutic device of the symbolic universe of sex dolls (De Fren; 2008; Smith, 2014; Wosk, 2015). Ovid's poem Pygmalion, the most well-known version of the mythical narrative, tells the story of the Cypriote king and sculptor, a celibate who despised and judged women as lustful and untrustworthy, who fell in love with a sculptured ivory female figure. The ivory creation was adored by Pygmalion for its beauty, lifelike and virginal appearance, which made it resemble a real embodied woman. Confessing his passionate state, Pygmalion prays to Venus, for which the Goddess' intervention grants the sculpture organic nature, movement and life. Although remaining unnamed in Ovid's Metamorphoses, the sculpture is named Galatea in subsequent versions of the narrative, such as in Rousseau's dramatic text Pygmalion, Scene Lyrique, from 1762 (Wosk, 2015). The mythical Ancient narrative has been highly influential in Western culture through the centuries: its expressions can be found in art, literature, theater and cinema (Smith, 2014; Wosk, 2015). 
The approach to contemporary sex dolls through the Pygmalion myth rests on the reconnaissance of a shared symbolic pattern that polarizes a male creator, active and desiring self, and his made and possessed creature, depicted as beautiful and passive (De Fren, 2008; Levy, 2008; Smith, 2014). The persistent and gendered asymmetry of Pygmalion's narrative could be seen as structurally continued by and projected into sex doll's imaginary, which would be anchored in the dichotomy of a masculine creator and a feminine second creature. In this contemporary framework, Venus is ultimately dispensable and replaced by high technology, autonomously able to produce a seemingly flawless lifelike appearance.

\section{COVERDOLL E-ZINE, METHODS AND APPROACH}

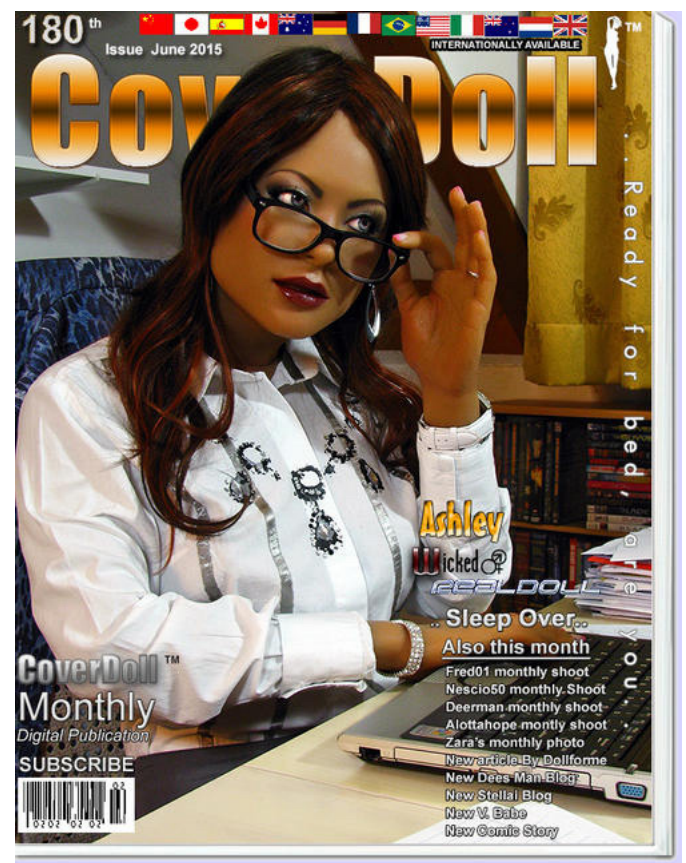

Figure 1: Cover of CoverDoll e-zine 180

Source: https://coverdoll.com/drupal/?q=node/2104

The online magazine CoverDoll was created in the year 2000. Thematically devoted to sex dolls - to which it refers as love dolls -, the e-zine "seeks to elevate and glamorize high end silicone love dolls to the status of $21^{\text {st }}$ century sculptures"'. Sex dolls, highly realistic synthetic sexual figures (although the sexual dimension is not the only, or even a necessary, one: Smith, 2014, p. 237) have met an unprecedented exposure, visibility and marketability, due to the current technological sophistication and the anonymity of online commercial transitions (Ferguson, 2010).

CoverDoll is a monthly e-zine internationally accessible. The digital magazine belongs CoverDoll Group, which comprises a constellation of websites, such as forums and virtual galleries, dedicated to the so-called love dolls. The magazine is produced and updated by the virtual community of dolls' owner and admirers.

\footnotetext{
' Retrieved from CoverDoll.com
} 
The online content of the magazine is restricted to those who express consent when visiting the website (which is announced as interdicted to underage people and not advised in case of particular susceptibility towards nudity or sexual content - although it is explicitly said that no pornographic content will be displayed). The full content remains restricted to registered users, the ones allowed to participate in the production of the magazine.

The internal structure of the e-zine does not follow an established and static format since its foundation; however, some sections remain constant. The section "On the Cover" focus on the love doll covering each number, presenting some detailed information about the doll and additional photographic portfolio. Other sections, such as "articles" - frequently about cinema -, "artistic folder", "virtual babes", "poster", "calendar", have also remained constant despite the e-zine's changes and evolution.

This article explores the gender representation underpinning the visual and linguistic content published in CoverDoll, aiming to analyse how female body and discourse's simulacrums are presented in the imaginary of sex dolls. The methodological approach combined two qualitative strategies, namely critical discourse analysis and a semiotic analysis. Both methods differently looked at the representations of the feminine underpinning the visual and linguistic content published on the magazine.

This study exclusively targeted the magazine's section "On the Cover", since this particular section contains not only a photographic production of sex dolls, but also a simulated questionnaire. The corpus comprises a sample of 180 editions, covering all the published "On the Cover" content between the 100" (June 2015) numbers of CoverDoll.

\section{Analysis. Digital Pygmalion and synthetic Galatea(s)}

The illusion of life underpinning the CoverDoll editorial project is anchored in a double simulation. The first expression of this "mimetic artificiality" (Smith, 2014, p. 241) is linked to the corporality, manifest in the high realism of the inorganic body; the other mimetic dimension is established through the discursive construction of a subjectivity, the rhetoric production of a personhood. The gendered anthropomorphism underpinning CoverDoll is visually and linguistically produced; femininity is fictionalized through body and discourse simulacrums.

Considering the double dimension of the artificial femininity, I propose the Pygmalion myth as the primal analytical device of CoverDoll. The representation of the female body is done through the obedience to stereotypical anatomic and aesthetical conventions: the dolls' face is always presented with long hair and often shown with applied make-up; the synthetic bodies are presented with curves, but never big-sized; the size of the breasts is frequently highlighted; when represented naked, the doll's (hairless) genitalia is also designed, corresponding to a so-called anatomical correction (Burr-Miller \& Aoki, 2013, p. 389) - illustrated by the Figures 2, 3 and 4: 


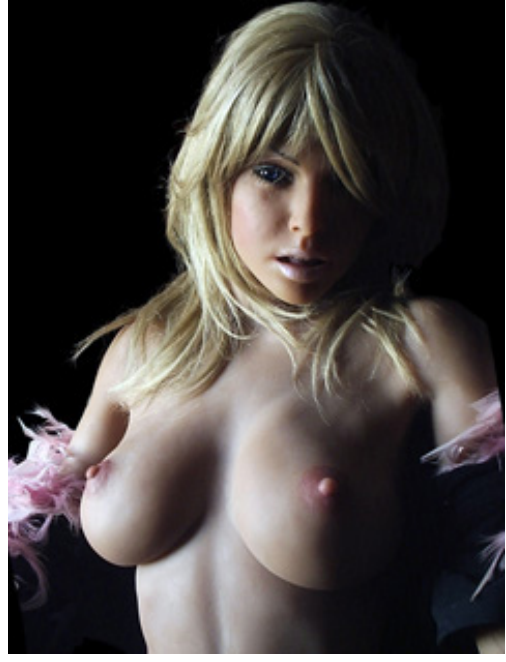

Figure 2: Misty; CoverDoll, 140 Source: https://coverdoll.com/drupal/?q=node/128

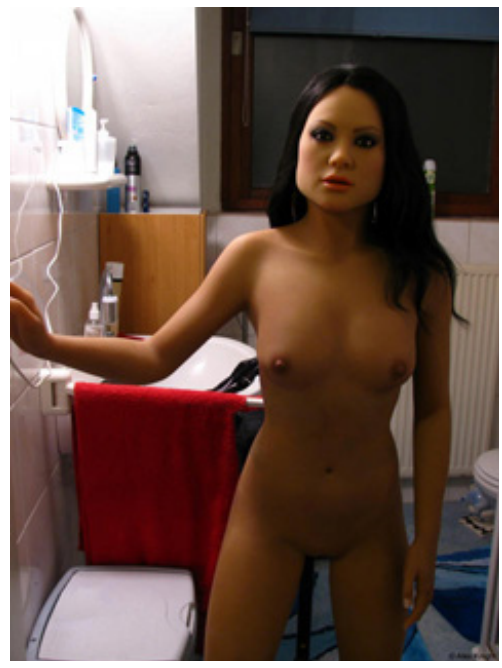

Figure 3: Kayla; CoverDoll, 147 Source: https://coverdoll.com/drupal/?q=node/1424

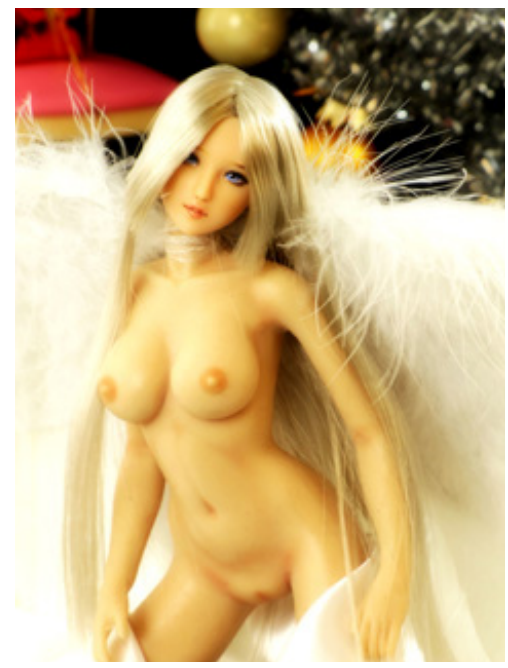

Figure 4: Fantasia; CoverDoll, 150 Source: https://coverdoll.com/drupal/?q=node/1484

\section{Simulating A SUbJeCtivity}

The section "On the Cover" follows a typified structure: under "CoverDoll profile" four textual categories are presented, identified as "Name", "Vital statistics", "Custom Features" and "Questionnaire". The attributed name is the first distinctive feature and individualizing device, as it works to individualize and differentiate each one of the dolls. The category "name" also includes the nickname, owner, locations and short bio. The reference to the doll's owner seems to disrupt the simulated biography, since it roots the referential framework in a reifying feature: having an owner is a defining feature of the dolls; they are ultimately identified as someone's possession. The location usually identifies a town and the respective country - being the USA the dominant geographical location cited, followed by Canada, France and the UK (although the veracity of the presented data cannot be guaranteed). 
The designated "short bio" is the decisive topic in the construction of a subjectivity: each doll is presented as having a biography, a personal story and identity. In few lines, the alleged age and itinerary (place of origin and current location) of the doll are presented, as well as some of their preferences and relational status. The short bio is sometimes expressed in direct discourse, while others transmitted as an impersonal narrative.

The simulation of a subjectivity seems slightly suspended or compromised by the next categories. In "vital statistics" and "personal features", the physicality of the dolls is carefully scrutinized: the measures of the bust, the waist, and the lips are revealed, the size of the breasts and the feet are exposed, as well as the doll's height and weight. The secondary features, such as the color of the eyes, the nails, the hair, the pubic hair and respective ornaments, are also meticulously expressed.

The questionnaire reopens the individualizing fictional process through a biographical inquiry. A typified set of topics cover different dimensions of the discursively forged subjectivity: dolls are questioned about their ambitions, their self-perceived qualities, their affections and preferences, their conceived perfect evening and favorite place. More intimate matters are also addressed, such as their most private and unconfessed fantasy, along with what makes them feel sexy and even the favorite sexual position. Different topics and themes are also covered, such as cultural predilections concerning music, arts, cinema, sports, television and literature.

The questionnaire suggests an intellectual respondent and autonomous subject, capable of reacting to cultural and affective stimuli and able to comment about music, books and paintings. The photographical productions, intertwined with the presented questionnaires, totalize Pygmalion's symbolic framework: the anatomical mimicry is captured by the visual dimension and parallelized by the discursive constructions, both promoting the illusion of an idiosyncratic personality.

\section{The FEMALE “BODY” AS A SPECTACLE}

Despite all the dialogic artifice, the objectifying framework is pervasive - primarily set by the allusion to the owner in the questionnaires (that establishes ownership as crucial identity feature of the dolls) and reinforced by the ubiquitous lexical references to the dolls' corporality.

The questionnaire item "my best quality" is frequently responded with direct mentions to the body or specific body parts: "my butt!" (Taylor, May 2015; Xiaoli, March 2015); "my face" (Emily, September 2010); "my breasts" (Karamira, January 2015); "my blue eyes, or so people tell me" (Miami, May 2012); "My legs, they go on forever" (Alektra, December 2010); "my mouth" (Reyna Dayana, September 2013). The physical predications and qualities are sometimes more diffusively referred: "A perfect body!" (Yurica, January 2014); "my soft skin" (Mami, February 2013); "soft and sensual" (Lilica, September 2012); "my curves" (Stracey, April 2013); "I like to think my personality, but I'll say my looks" (Ally, April 2015). Some of the answers express hesitation regarding the privileged quality, oscillating between different possibilities and body parts: "my hair I guess, that's 
what most people say. Maybe my eyes. I don't know. DB [owner] says my butt..." (Danielle, June 2010); “my flexibility. Incred [owner] says my butt..." (Yoshi, May 2010).

The last two questions explicitly echo an external valorization, internalized by the fictional responding subjects. The fiction of self-image and self-appreciation are dependent on the value attributed by their owner: it's the external gaze that grants the female subjects their own identity and self-perception. Fictionalized female respondents internalize their role as something to be perceived and looked at, converging with John Berger's diagnosis (1972) in Ways of Seeing:

men act and women appear. Men look at women. Women watch themselves being looked at. This determines not only most relations between men and women but also the relation of women to themselves. The surveyor of woman in herself is male: the surveyed female. Thus she turns herself into an object - and most particularly an object of vision: a sight. (Berger, 1972, p. 47)

The construction of the feminine as a visual object is the cornerstone of Coverdoll: the female body is presented as a spectacle, a surface and ornament (Bartky, 1988). Its aesthetics, pose and constitution reflect specific and restrict prescriptions and codes: the slimness imperative (Bordo, 1993), the perfect and hairless skin, the avoidance of imperfections or age signs (Bartky, 1988). The simulated self-awareness that emerges from fictional narratives echoes the self-vigilance described by Bartky (1988): the extrinsic but internalized male gaze dismisses external mechanisms of control, as self-vigilance is enough and effective in monitoring and constraining the movements. The fictional female identity expressed through the questionnaires looks at herselfbecause she is looked at, while the one observing her stands as a voyeur, an outsider and spectator - but he is the one determining the image. Berger's analysis on the representation of nudity across the European tradition of oil painting seems again suitable in the contemporary context of CoverDoll's pictorial framework:

the principal protagonist is never painted. He is the spectator in front of the picture and be is presumed to be a man. Everything is addressed to him. Everything must appear to be the result of his being there, it is for him that the figures have assumed their nudity. But he, by definition, is a stranger with his clothes still on. (Berger, 1972, p. 54)

Body, femininity and spectacle are symbiotically constructed: the feminine is shaped and forged as an image to be consumed by an external subject. The structural imparity between the one who is exposed and the one who gazes is not represented as a source of discomfort; on the contrary, the fictional awareness of being looked at is represented as a source of pleasure and self-reward: "her own sense of being in herself is supplanted by a sense of being appreciated as herself by another" (Berger, 1972, p. 46). The absence of the external gaze, touch and attention seems to condemn the love dolls to a state of ontological suspension: illustratively, when asked about she hates, Kaylani Lei simply answers "to be ignored" (August, 2011). 


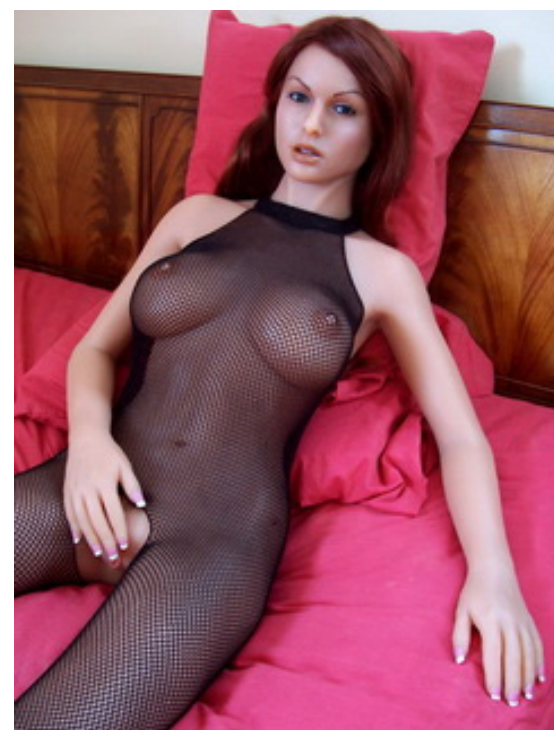

Figure 5: Phoebe, CoverDoll, 104

Source: https://coverdoll.com/drupal/?q=node/484

Figure 5 shows doll Phoebe laying on a bed, a position typically understood as a "conventionalized expression of sexual availability" (Goffman, 1976, p. 41). The transparent fabric reveals her body shape, particularly the genitalia, due to its opening. The doll directly faces the camera, establishing visual contact. At the same time, her right hand is placed on the genitalia, a gesture that invokes masturbation. The intertwinement of this positioning with the simulated visual contact renders the masturbatory act, along with its potential pleasure, an externally determined and oriented meaning: they are, firstly and foremost, a visual spectacle, programed to be enjoyed by the (male) absent subject on the picture. The simulation of self-oriented pleasure is, ultimately, a visual recreation for the male spectator. The female figure is not pleasing herself: her fictional self-arousal and pleasure are in fact meant to please the other; her own pleasure serves the main purpose of the spectator's satisfaction.

\section{FROM THE MIRROR TO THE CAMERA: SIMULATIVE DEVICES OF FEMALE NARCISSISM}

The questionnaires present multiple references to the camera, along with allusions to an external gaze and photographic productions. When asked about what makes them feel sexy, the answers often converge: "The photographer just stops shooting and looks at me" (Xioli, March 2015); "a camera is pointing at me" (Jenna, August 2014); "[when] "I'm in front of the camera and knowing people will be checking me out" (Tamara, June 2014); "[when] "Fred looks at me and when he takes my pictures" (Yurica, January 2014); "[when] "I think about all of the eyes on the other side of the camera" (Belinda Josephine, October 2013); "[when] I am being photographed" (Kylie, April 2012).

The camera works as a primer symbol of visuality in CoverDoll, establishing an asymmetrical and unequal gendered visual relationship between the one who glances and the one who is looked at. The male gazer is kept outside, unexposed; the female 
body is the object of his vision. In this equation, the camera seems invested with the role previously assumed by the mirror, in Berger's description: "the mirror was often used as a symbol of the vanity of woman". This "moralization" was, in the author's words, "mostly hypocritical":

\begin{abstract}
you painted a naked woman because you enjoyed looking at her, you put a mirror in her hand and you called the painting Vanity, thus morally condemning the woman whose nakedness you had depicted for your own pleasure. The real function of the mirror was otherwise. It was to make the woman connive in treating herself as, first and foremost, a sight. (Berger, 1972, p. 51)
\end{abstract}

It is possible to draw a parallel between the operating mechanisms in the tradition of painting, as described by Berger (1972), and the visual construction of the love dolls on CoverDoll: the inorganic bodies are displayed because of an outsider's will or demand; the female vanity is in fact projected by the observer. This process is even more flagrant in CoverDoll's context: since the displayed bodies are in fact mannequins, the simulated narcissism is an unambiguous projection over the female figures by an external and presumably male gazer. The feminine is reified as "an object to be looked at, a sensorial spectacle, a visual screen onto the most diverse fantasies are projected" (Pinto-Coelho, 2007 , p. 176). The camera is, therefore, a substitute for the mirror as a symbolic device in the representation of female narcissism.

The persistent reference to the camera, as a symbol of self-representation and visual performance, is intrinsically linked to the discursive construction of the seductive and tempting female. Considering the e-zine's framework, this archetypical prevalence is hardly surprising; however, some of its discursive expressions are worth analyzing, especially when articulated with other characterizations revealed by the questionnaires.

\title{
STEREOTYPING THE FICTIONAL FEMALE FIGURE: SEDUCTION, BEAUTY, FUTILITY AND CARE
}

The imagery of the female seducer is the representational centerpiece of CoverDoll, which is expressed in several stereotypical frames. Honor, pictured blindfolded, says she loves to "disguise [herself] as femme fatale!" (June, 2011). Kamira, referring to the untold fantasy, exclaims "orgy session!"; further, when questioned about what she enjoys, she states "Kinky Cosplay"; regarding what she cannot imagine to have enough, she answers "flavoured condoms"; coherently, she identifies "BDSM" as her favorite sport (January, 2015). The same discursive pattern is found in Jessica's questionnaire: her ambition is identified as "[transferring] from Adult porn star to erotica star"; she claims to hate "premature ejaculation" and identifies "strip poker" as her idea of fun (July, 2010). The oversimplified, reiterated and standardized sexual portray that comes to light from these quotes and questionnaires reduces the figure of the seducer, and female sexuality more broadly, to a caricatural representation. The pictorial devices overall eroticize of the portrayed female figures, a process illustrated by the Figures 6 and 7: 


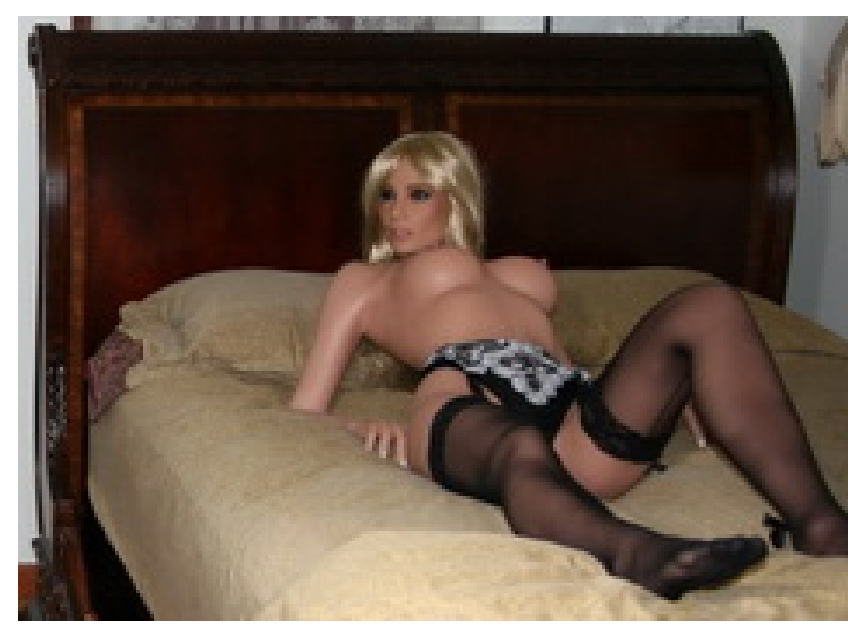

Figure 6: Jessica; CoverDoll, 121 Source: https://coverdoll.com/drupal/?q=node/939

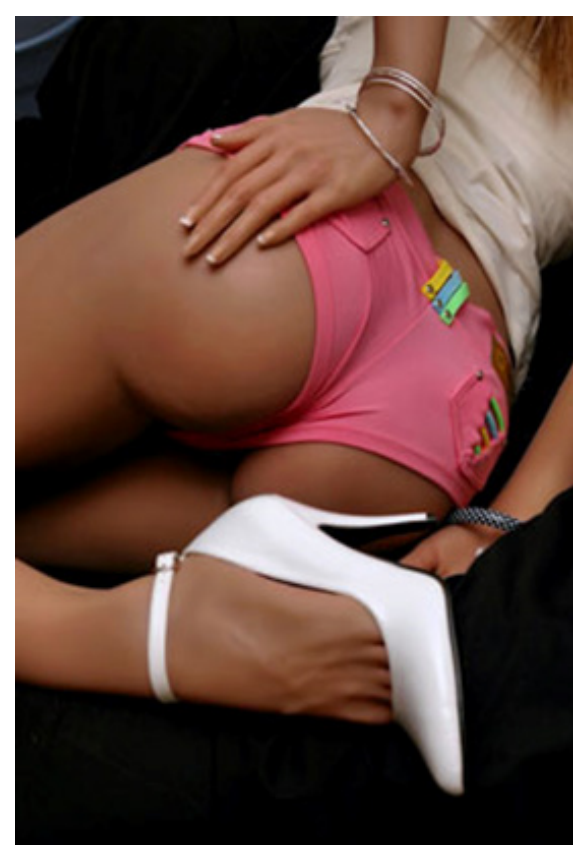

Figure 7: Fantasia, CoverDoll, 110

Source: https://coverdoll.com/drupal/?q=node/686

Jessica is portrayed laying on a bed, supported by her arms (Figure 6). The contextual element suggests intimacy and the physical positioning is connoted with sexual availability. The doll does not face the camera, and her left leg is partially lifted. The eroticization of the bodily pose is reinforced by the partial nudity, aligned with the few garments wore by the doll, which is presented using only garter lingerie.

Figure 7 centers the doll's buttocks, by omitting her face and solely showing her back. Fantasia is shown wearing shorts that allow a partial gluteal exposure. Her left hand is placed on the buttocks, suggesting a voluntary and self-induced eroticized position. The exposed high heel shoe is erotically connoted when articulated with the remaining graphical elements. Besides hiding the face, the image conceals the upper body and part of the legs. The fragmentation of the body and the suppression of the face induce the objectification: "[the face] and all the body except the buttocks are excluded from the picture. However, the observer is set close to these body parts, which potentiates its better visualization. [The portrayed female] is nothing but buttocks, adorned buttocks" (Mota-Ribeiro, 2005, p. 142).

The primal stereotype, related to the seducer figure, is intertwined with other stereotypical feminine profiles: the decorative beauty, the caring and the frivolous female. The representation of female beauty is intertwined with the stereotype of seduction and linked to the multiple allusions to fashion, beauty and consumption across the biographic notes and questionnaires.

Underpinning the visual and linguistic representations of CoverDoll, beauty is represented as the ultimate female capital. Some of the fictional identities are presented as amateur or professional models: "when she is not odelling, she is a botanist" (Fantasia, December, 2012); "I've been a photographic model for seven years and hope to go on 
for another seven years" (Misty, February 2012). Personal ambitions and motivational prospects are frequently fictionalized in accordance to the same referential background: "To be a high fashion model" (Andrea Rose, January 2012); "be a model and make full of magazine's cover" (Honor, June 2011); "To become a great star in fashion business" (Laura, April 2011). The questionnaire's item regarding what they love presents congruent references: "Shopping! Buying new lingerie on the internet and spend Musician's [owner] money" (Roselle, February 2010); "Clothes" (Alektra, December 2010); "the transparency, the subdued lights, the clothes, the perfumes, the champagne and the Macallan Whiskey" (Honor, June 2011); "heels, beautiful lingerie, being sexy" (Lilica, October 2012); "Piano music, Fashion, and Muffins" (Xiaoli, March 2015).

The female beauty widely celebrated through the magazine is not a pluralistic one, able to cover a plethora of bodily shapes and expressions. On the contrary, female beauty is narrowly conceived and portrayed, mostly anchored in youth and slimness - as exemplified by the figures 8 and 9 . The beauty imperative (Wolf, 1991) is translated into a standardized and monolithic aesthetical ideal; the eroticization of the synthetic bodies is achieved by highlighting the breasts, the curves, the thin waists, the long hair and the slimness of the dolls.

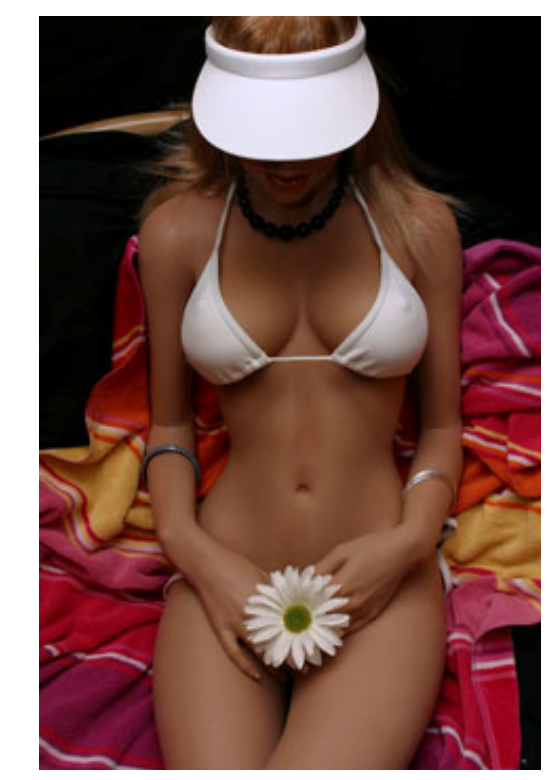

Figure 8: Fantasia, CoverDoll, 110 Source: https://coverdoll.com/drupal/?q=node/686

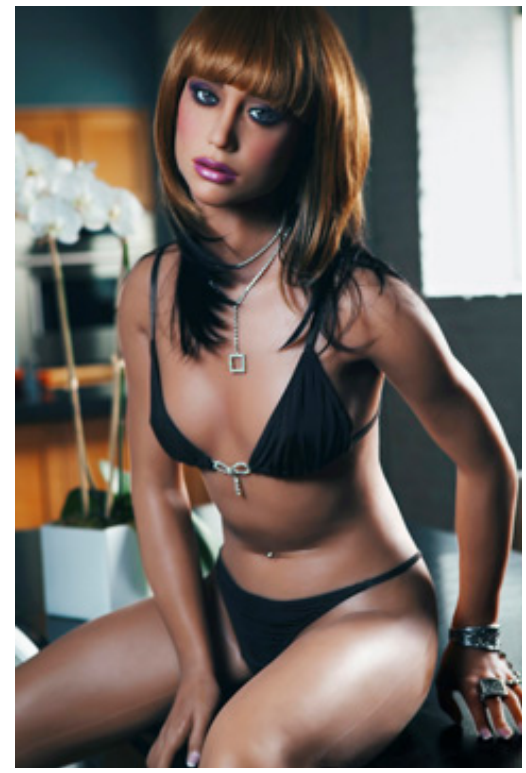

Figure 9: Crystal, CoverDoll, 144 Fonte: https://coverdoll.com/drupal/?q=node/1379

In figure 8, Fantasia is shown lying in what seems to be a beach towel, over a black framework. The white cap partially covers her face, only exposing the lips and the chin. The graphical predominance of the white color evokes the idea of youth and purity, suggesting a diffuse idea of virginal appearance. This is reinforced by the bodily position: the arms are symmetrically positioned over the upper body, and the hands are shown keeping a white flower; the suggestion of the bodily constraint suggests a certain shyness and diffidence. The body is thin and fit, and the image is centered by her narrow waist. The 
white flower placed over the genitalia contributes to the imaginary of youth, fragility and innocence - not only through the color effect, connoted with purity, but also through the flower's symbolism, associated with blossoming and the birth of a new cycle or season.

Figure 9 portrays Crystal seating on a table; the doll is shown wearing a bikini and several accessories: a necklace, a bracelet, several rings and a glowing piercing. Her body is slim and fit. Her appearance and posture invokes a certain fragility and insecurity: instead of firmly positioned, her left hand timidly touches the table's surface, merely touching it with the tip of her fingers. This suggestion of hesitation or insecurity is enhanced by the slight inclination of the head, which can be read as an expression of submission, subordination or appeasement (Goffman, 1976, p. 178). The face with make-up looks young; the direct visual interaction suggests contact, as if directed to the external observer.

The affective dimension is often underlined in the fictional discourses, prompting the stereotype of the caring female role. The fictional self-image is sometimes merged with the relational status: when questioned about the main quality, many answers allude to the capacity of giving, caring and pleasuring their partners: "the love I give to my hubby" (Andrea Rose, January 2012); "I'm always there to please you" (Sacha, November 2012); "My gentle inner nature" (Chaiama, July 2012), "I'm great at taking care of my man, in every aspect of life" (Brigitte, March 2014).

Female fictional narratives often praise and underline the capacity to please the male partner, either by care, lust or emotional support. These are multiple expressions of devotion to a partner and romantic loyalty, such as the ones mobilized when responding to a description of a perfect evening: "A good movie, dancing, dinner, admiring stars under the moon light and stimulating conversation" (Breanna, March 2010); "Crouched by the front door, listening for him to come home" (Miami, May 2012). The question regarding the favorite place also invoke affective and romantic expressions: "in Charley's [owner] arms!" (Ele, October 2010); "by the Sea and by my Man" (Grace, July 2014); "right where I am now, in my lover's home" (Andrea Rose, January 2012); "Alex's [owner] place, of course!" (Kayla, September 2012).

Lastly, frivolity emerges as another core stereotyped feature in the feminine fictional portray, especially detectable when inquiring about the favorite authors and books. Plenty of sarcastic expressions are found, as well as repulsive reactions towards reading preferences: "Playboy", Yoshi (Yoshi, May 2010); "don't read much, I'm more of an action girl", (Alektra, December 2010); "cooking books" (Anoukis, April 2013); "I read Cosmopolitan, Allure and other fashion magazines" (Reyna Dayana, September 2013); "Not a big reader but I like looking at nice pictures" (Danielle, February 2014). An infantilizing tone is sometimes found across the questionnaires, detectable in some particularly childish answers: "who wrote the internet?" (Lissa, December 2013); "Stephen King, Deane Koontz... scary stories, but I can't read them when I am alone because then I can't sleep" (Danielle, June 2010). The same infantilizing device is observable regarding the answers provided about artistic preferences: "the fellow who painted our kitchen and living room" (Mia Okinawa, December 2014); “oh, what's that one by Van Glock? The one with the flowers in it" (Xiaoli, March 2015). 
Even when a potential counterexample is presented - such as Varvara, embodying the intellectual profile -, the anecdotal tone underpinning its representation does not inflect the dominant female portray. The label of "the intellectual cougher" induces a caricature of the intellectual female figure, along with the eroticization of a social female role allegedly alternative in the dominant representational economy of CoverDoll. Her fictional biography describes her as highly educated, having emigrated from Russia to the UK with the purpose of teaching her native language and history at the British academy. Despite this profile, the alleged biggest quality resends her narrative to the corporality: "slim body with slight belly bulge". The fictional questionnaire exhaustively repeats the same formulation, despite the different questions addressed: "reading War and Peace in the library" is the prototypical answer, given to a large spectrum of questions - such as the idea of a perfect evening, the conception of fun, the idea of aphrodisiac and what she loves. The simplistic portray of the female intellectual seems to empty the alternative representation and to reduce it to a cliché.

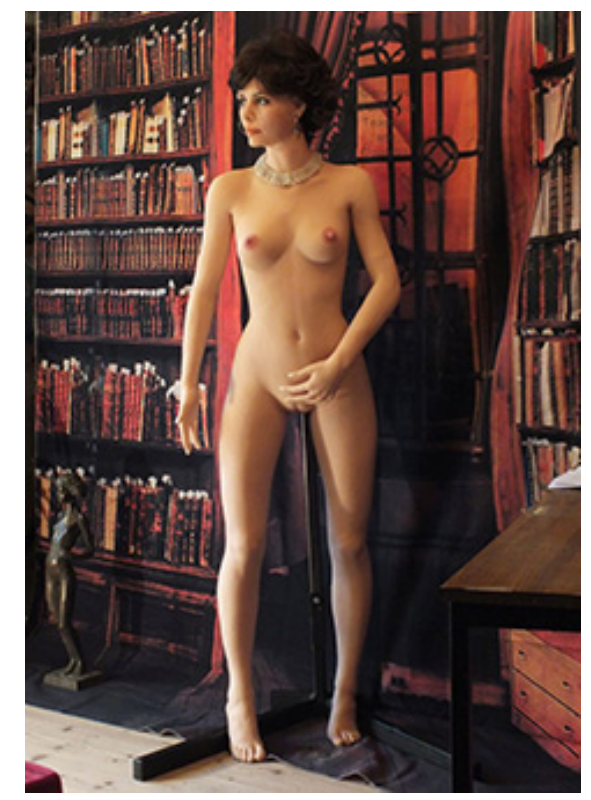

Figure 10: Varvara, CoverDoll, 171 Source: https://coverdoll.com/drupal/?q=node/1949

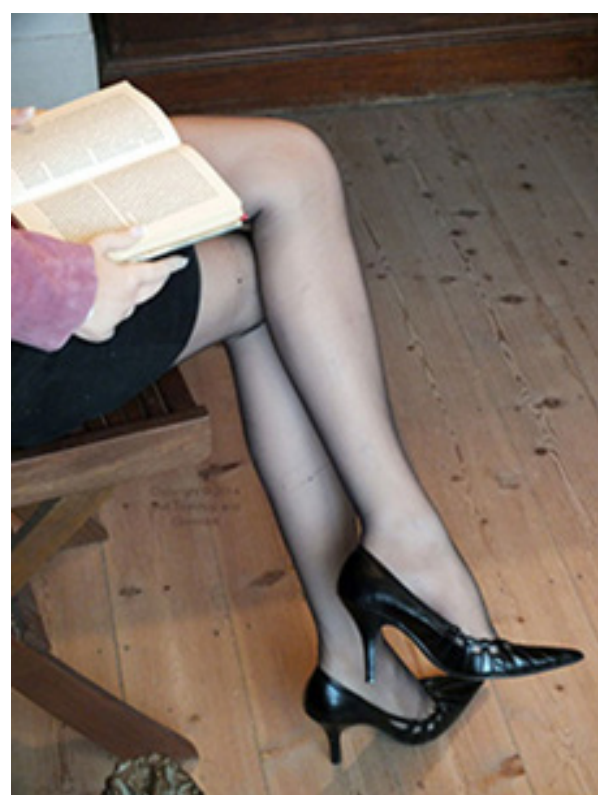

Figure 11: Varvara, CoverDoll, 17 Source: https://coverdoll.com/drupal/?q=node/1949

The pictorial construction is equally expressive. Varvara is portrayed in what resembles a library, a context allusive to academia (Figure 10). Some shelves with books are shown behind her, and a desk is partially observable on her side. Despite the contextual background, Varvara is fully naked, only wearing a necklace. The frontal nude contrasts with a slight inclination of the head, a positioning that evokes distraction and detachment. The left hand is placed above the genitalia, which suggests touch and physical contact and largely contributes to the eroticizing effect of the picture. The spatial element - the library - does not restrain or conflict with the eroticization of the image; on the contrary, the subversion of the typical purpose assigned to the surrounding area seems to reduce the prototype of the intellectual figure to a caricature. 
In figure 11, Varvara is only partially pictured and shown seating on a chair. Her legs are the central graphic element, over which an open book is shown, placed over the doll's lap and hold by her hands. Several elements contribute to the eroticization of the image: the graphical suppression of the face and the upper body, along with the crossed legs, the transparent leggings and the black high heels. The fragmentation of the body disposal is again adopted as a visual strategy that enhances the objectification of the female figure (Goldman, 1992, p. 121; Mota-Ribeiro, 2005).

\section{Concluding Remarks. Digital Pygmalion: new screens, old ways of Seeing?}

The representational framework of CoverDoll seems anchored in paired antagonisms: the one who gazes and the one who is gazed upon correspond to the one who desires and the one who is desired. The dualistic structure underpinning this symbolic construction can be synthetically formulated in terms of a gendered fictional representation: men desire, women are aware of such desire, and internalize their self-award from such perceived desirability. Men look at women, and women acquire their self-awareness and sense of identity by the perceived fact of being looked at.

Desire and power are fused and reciprocally invested Masculinity is represented as fundamentally agentic; it is constructed as desiring, active and creative. Female desire is differently depicted: it is mostly anchored in the archetypical representation of the femme fatale or, alternatively, rooted in the romantic representation of the passionate, loyal and devoted female partner. Both processes and representations work differently to picture heterosexuality as essential (Pinto-Coelho e Mota-Ribeiro, 2012, p. 208).

The condition of alterity ascribed to the feminine seems not only maintained, but also refreshed, in the virtual environment of the e-zine. The fictional discourses that support the simulation of a subjectivity presume both a male authorship and a male audience, rendering the expression of the feminine a resemblance of literary ventriloquism.

CoverDoll e-zine seems to testify the persistence and projection of conventional symbolic codes and stereotyped conceptions regarding the gendered body. This continuity, despite technological disruption, seems to contradict the first theoretical premises of cyberfeminism that celebrated the emancipatory potential of cyberspace. The body is not neutralized, suspended or absent in the analyzed digital publication; its representation reproduces conventional visual grammars and gender roles. CoverDoll's pictorial background seems to reflect the reintroduction of the body in cyberspace referred by Jessie Daniels, due to the contemporary features of image and video-based online platforms. CoverDoll seems to provide new screens for some ancient and conventional symbols and meanings. The persistence of the ways of seeing despite the discontinuity of the media environments and supporting platforms was previously addressed by Berger:

today the attitudes and values which informed that tradition are expressed through other more widely diffused media - advertising, journalism, television. But the essential way of seeing 'women, the essential use to which their images are put, has not changed. Women are depicted in a quite different 
way from men - not because the feminine is different from the masculine

- but because the 'ideal' spectator is always assumed to be male and the image of the woman is designed to flatter him. (Berger, 1972, pp. 63-64)

The photographic production and imagery construction in a digital landscape do not point to a more fluid gender representation. On the contrary, the pictorial and linguistic devices presented in CoverDoll seem to translate a reinvestment of highly stereotypical gendered cultural forms. CoverDoll's analyzed portfolio reflects an idealizing process of the female aesthetical that not only impoverishes, but ultimately dehumanizes, it - even if such dehumanization comes aligned with the unprecedented illusion of life launched by contemporary technological production.

Finally, considering the fictional framework of CoverDoll, it could be argued that its representations are structurally forged within a simulative, theatrical and ironic framework that could largely contest, or even subvert, the identified depictions and dominant meanings. However, even if such a criticism comes as expectable and legitimate, such hypothetical subversion impelled by its humoristic tone should not detain us from critically analyzing the fictional representations displayed (such argument could, otherwise, immunize any fictional productions from scholar scrutiny). Moreover, I argue that the arguably humoristic approach presented in CoverDoll testifies Gill's diagnosis of irony as an increasingly prevailing device in the presentation of sexism, which not only provides an easy rhetorical shield to potential feminist criticism but also allows a counter-criticism by labeling it humorless (Gill, 2007, p. 82).

Translated by Maria João Faustino

\section{BIBLIOGRAPHIC REFERENCES}

Bartky, S. L. (1988). Foucault, femininity, and the modernization of patriarchal power. In I. Diamond \& L. Quinby (Eds.), Feminism Q Foucault: Reflections on resistance (pp. 61-86). Boston: Northeastern University Press.

Berger, J. (1972). Ways of seeing. London: Penguin.

Bordo, S. (1993). Unbearable Weight: Feminism, Western Culture, and the Body. University of California Press.

Burr-Miller, A., \& Aoki, E. (2013). Becoming (hetero) sexual? The hetero-spectacle of idollators and their Real Dolls. Sexuality o Culture,17(3), 384-400.

Daniels, J. (2013). Rethinking Cyberfeminism(s): Race, Gender, and Embodiment. Women's Studies Quarterly, 37, 101-124.

De Fren, A. (2008). The Exquisite Corpse: Disarticulations of the Artificial Female. ProQuest

De Fren, A. (2008). The Exquisite Corpse: Disarticulations of the Artificial Female. PHD Dissertation, University of Southern California, California, United States of America. Retrieved from http://digitallibrary.usc.edu/ $\mathrm{cdm} / \mathrm{ref} /$ collection/p1579gcoll127/id/123923.

Ferguson, A. (2010). Sex Doll: a History. Jefferson: McFarland \& Co. 
Gill, R. (2007). Gender and the Media. Cambridge: Polity Press.

Goffman, E. (1976). Gender Advertisements. New York: Harper Goldman.

Goldman, R. (1992). Reading ads socially. London: Routledge.

Hansen, M. (2006). Bodies in Code: Interfaces with Digital Media. New York: Routledge.

Haraway, D. (1985). A Manifesto for Cyborgs: Science, Technology, and Socialist Feminism in the 8os. Socialist Review, 80, 65-108.

Levy, D. (2008). Love and sex with robots. New York: Harper Collins.

Nakamura, L. (2002). Cybertypes: Race, Ethnicity, and Identity on the Internet. New York: Routledge.

Mota-Ribeiro, S. (2005). Retratos de mulher. Construções sociais e representações visuais no feminino. Porto: Campo das Letras.

Pinto-Coelho, Z. (2007). Imagens publicitárias: jogos do olhar, género e sexualidades. Comunicação $e$ Sociedade, 11, 175-184. doi: 10.17231/comsoc.11(2007).1140

Pinto-Coelho, Z. \& Mota-Ribeiro, S. (2012). O reino do casal heterossexual na publicidade: uma análise sociosemiótica das estratégias visuais e das inscrições discursivas. Comunicação e Sociedade, 21, 205214. doi: 10.17231/comsoc.21(2012).709

Plant, S. (1997). Zeroes and Ones: Digital Women and the New Technoculture. London: Fourth Estate.

Price, J., Shildrick, M. (1999). Feminist Theory and the Body. A Reader. New York: Routledge.

Smith, M. (2013). The erotic doll: a modern fetish. New Haven: Yale University Press.

Turkle S. (1995). Life on the Screen: Identity in the Age of the Internet. New York: Simon \& Schuster.

Wolf, N. (1991). The beauty myth. London: Vintage Books.

Wosk, J. (2015). My Fair Ladies: Female Robots, Androids, and Other Artificial Eves. New Jersey: Rutgers University Press.

\section{WEBGRAPHY}

CoverDoll (2009, February) Phoebe. CoverDoll nº104. Retrieved from https://coverdoll.com/ drupal/?q=node $/ 484$

CoverDoll (2009, August) Fantasia. CoverDoll nº110. Retrieved from https://coverdoll.com/ drupal/?q=node $/ 686$

CoverDoll (2010, July) Jessica. CoverDoll nº 121 . Retrieved from https://coverdoll.com/drupal/?q=node/939

CoverDoll (2012, February) Misty. CoverDoll nº140. Retrieved from https://coverdoll.com/ drupal/?q=node/1281

CoverDoll (2012, June) Crystal. CoverDoll n 144. Retrieved from https://coverdoll.com/drupal/?q=node/1379

CoverDoll (2012, September) Kayla. CoverDoll nº 147 . Retrieved from https://coverdoll.com/ drupal/?q=node/1424 
CoverDoll (2012, December) Fantasia. CoverDoll nº150. Retrieved from https://coverdoll.com/ drupal/?q=node/1484

CoverDoll (2014, September) Varvara. CoverDoll $n^{\circ} 171$. Retrieved from https://coverdoll.com/ drupal/?q=node/1949

CoverDoll (2015, June) Ashley Denari. CoverDoll nº ${ }^{\circ} 80$, Cover. Retrieved from https://coverdoll.com/ drupal/?q=node/2104

\section{FinANCIAL Support:}

Scholarship PD/BD/105812/2014 from the Portuguese Foundation for Science and Technology.

\section{BiographicAl Note}

Maria João Faustino is a PhD candidate at the University of Auckland. Her doctoral research focuses on sexual violence, its gendered dynamics and the changing sexual scripts of heterosex. Her research interests include feminist media studies, technosexuality and feminist approaches to sexuality.

E-mail: Mjcpfaustino@hotmail.com

The University of Auckland, Private Bag 92019, Auckland 1142, New Zealand

* Submitted: 14-08-2017

* Accepted: 03-11-2017 